\title{
Analysis of the Temporal and Geographical Transferability of Disaggregate Hurricane Evacuation Demand Models of Different Model Specification
}

\author{
Ravindra Gudishala ${ }^{1}$ and Chester Wilmot ${ }^{2}$ \\ ${ }^{1}$ Research Associate, Department of Civil and Environmental Engineering, \\ Louisiana State University \\ ${ }^{2}$ Professor, Department of Civil and Environmental Engineering, \\ Louisiana State University \\ ${ }^{1}$ rgudis1@lsu.edu, ${ }^{2}$ cecgw@lsu.edu
}

\begin{abstract}
This research paper reports on findings from an empirical study that examined the effect of model specification on temporal and geographical transferability of evacuation demand models from one context to another. The evacuation demand models, all of them of the time-dependent nested logit model (TDNLM) type, were estimated on data from hurricane Gustav in New Orleans in 2008, and temporally and geographically transferred to conditions surrounding hurricane Andrew in southcentral Louisiana in 1992. Six model specifications were used to investigate the relationship between transferability and model specification. Findings reveal that the model specification that accounted for four time periods in a day and transformed dynamic distance to the storm by means of a lognormal distribution, performed best as measured by metrics used to measure transferability. The best specified model estimated on Gustav data and transferred to Andrew predicted that out of a total of 133 households in the Andrew sample, 87 households would evacuate when 72 were observed to evacuate. The diurnal fluctuation in evacuation closely matched the observed pattern although the transferred model over-predicted on the first day (22 predicted, 11 observed). The root mean square error for the best model specification was 3.5 household evacuations per six-hour time period over a total of 14 time periods. The model with the poorest model specification predicted a total of 90 household evacuations with a root mean square error of 6.3 household evacuations per six-hour time period. It reproduced the observed diurnal fluctuations even though some time of day variables were eliminated from the model specification. However, it over-predicted on the first and second days $(23$ predicted versus 11 observed on the first day, and 39 predicted versus 28 observed on the second) and under-predicted on the third (25 predicted versus 33 observed). The transferred model predicted 3 households would evacuate on the fourth day when none were observed to evacuate on that day. Overall, the results indicate that improved model specification lead to improved transferability in this case and that a geographically and temporally transferred evacuation demand model was able to estimate the time-dependent evacuation decision of 133 households over 14 time periods with an average error of 3.5 households per time period.
\end{abstract}

Keywords: Evacuation demand model, transferability, evacuation demand modeling. Evacuation planning

\section{Introduction}

Evacuation planning relies extensively on forecasts of evacuee's behavior over time. One of the implicit assumptions made in making forecasts using behavioral models is that 
an evacuee's response to stimuli prompting behavior is constant over time. In the context of discrete choice modeling, this amounts to assuming that a respondent's "tastes", or the value they assign to the attributes of each choice, remain stable over time. This assumption, made in predicting future conditions, is an assumption of temporal transferability of the behavioral model being used. Although this assumption is essential and necessary in making forecasts of future behavior, it is not necessarily always true. Furthermore, when the behavior on which a model is based is not the result of repetitive exposure to conditions in which alternative choices can be evaluated, then the validity of the assumption can be questioned, as described in the next paragraph.

Hurricanes are low probability and high consequence events. Consequently, residents of a threatened area do not get the opportunity to repeatedly participate in evaluating the evacuation decision. Thus, the utility maximizing theory on which behavioral models are based would seem ill-suited to this situation given hurricane events do not provide residents the opportunity to establish tastes or attitudes regarding evacuation choices. However, an empirical study conducted by Murray et. al., [1] reported that residents do not change their preferences or behavior when repeatedly faced with an imminent threat from storms over time. Thus, given this inconsistency between empirical findings and intuitive judgment about future evacuation behavior it becomes imperative to test the validity of the temporal transferability assumption in the context of an emergency. Furthermore, there are additional benefits that can be gained when transferring demand models such as not needing data on which to estimate a local model and being able to establish a model quicker.

The benefit of transferring a demand model across geographic areas is obvious. Given the time, cost and opportunity to collect evacuee behavioral data and estimate a model in each location, it is preferable to have a demand model that could be transferred across location and time rather than having to repeatedly collect data for estimating a new model. Having such a model allows one to repeatedly use the model to test and evaluate evacuation alternatives for each new geographic region of interest.

Another advantage is that accurate predictions of evacuation behavior will build confidence emergency managers and other public officials have in technical analysis of alternative evacuation policies that rely extensively on forecasts of evacuation behavior. Researchers working in the evacuation demand modeling area have used utility maximizing theory to develop evacuation demand models using various mathematical specifications and predictor variables. For instance, Dixit, Wilmot \& Wolshon 2012 [2] have used a risk attitude preference framework to model departure time choices, Hasan and Ukkusuri [3] have used a logit modeling framework to model evacuation choices, and $\mathrm{Fu}$, Wilmot and Baker [5] have used a sequential-logit framework to predict timedependent evacuation choices of households. A recent increase in the number of models that predict evacuation behavior, highlights the belief researchers have placed in such models' role in alternative evacuation policy assessments. Despite developing such complex mathematical models there have been relatively few studies that have tested the temporal and geographic transferability of evacuation demand models. This paucity of information was the major motivation in conducting the empirical study reported in this paper.

\section{Literature Review}

Evacuation modelers or analysts with transportation engineering background have often employed rational choice theory or utility maximizing theory [6] and viewed risk area residents as utility maximizer's and subsequently modeled their choices using the mathematical frame work associated with it. However, only two studies so far have conducted the analysis to test the validity of the temporal/geographical transferability assumption in evacuation demand models. One study conducted by $\mathrm{Fu}$, Wilmot, and 
Baker [5] has tested the transferability of a time-dependent sequential logit model and concluded that the model is spatially transferable to a certain extent and suggested updating model parameters when application context data is available to improve the accuracy of the transferred models.

The other study by Sadri et al [7] investigated the notion of transferability using a joint modeling approach and pooled data from three hurricanes to develop a joint model to test the transferability of a discrete choice model that explains evacuation behavior of households. The research concluded that the transferability of models developed using utility maximizing theory is possible if an evacuation behavior model used for making forecasts is calibrated using both estimation context and application context data. However, both of the studies suffer from a disadvantage namely that some form of knowledge about application context is assumed to exist when transferring a model from estimation context when in reality this is usually not the case.

While quantification has been the primary approach of engineers, social scientists have used the qualitative, theoretical approach to explain evacuation behavior. There are two major theoretical models advanced by social scientists to explain evacuation behavior: first the warning response model developed by Sorensen and Mileti [8] and the protective action decision model (PADM) developed by Lindell and Perry [9]. Lindell has tested the PADM theory in two hurricane evacuation contexts $[10,11]$. His findings indicate evacuation behavior is consistent in general with PADM. However, the quantitative aspects of evacuation demand have not been addressed in either of these studies. This study is an attempt to provide quantitative evidence of transferability lacking in these studies.

\section{Methodology}

\subsection{Data Description}

The data used in this study was collected by two separate data collection efforts by two research groups. Irwin and Hurlbert collected the data for Hurricane Andrew in November of 1995 following the occurrence of Hurricane Andrew in 1992 [12]. The study used telephone numbers as a sampling frame to sample 651 residents from a total of 24 coastal parishes in Louisiana. The study collected responses to about 40 questions that were related to evacuation behavior. The behavioral data collected in the survey was supplemented with Hurricane Andrew's time-dependent data available on the National Hurricane Center's website. Additionally, the data related to the actions taken by emergency managers were gathered using newspaper archives.

The assumption made about information available in the application context plays an important role in assessment and measurement of transferability. One of the important pieces of information needed when applying a model is information on the time and type of evacuation orders that were in effect at any given time for each household. Because the application data set (Hurricane Andrew data) had this information available in its data set the information reported by each household in their response were utilized in coding the data used for application of models. As such, only the households that reported such information were considered for inclusion in the application data set. It is interesting to note that out of the 651 households that were included in the total sample only 193 households had all the required information needed for applying the models and moreover, only 133 households out of 193 households included information about their perception of whether an evacuation order was in effect for their jurisdiction when Hurricane Andrew struck. Thus, data from only 133 households were used to test the transferability of models developed in the previous section.

The data related to hurricane Gustav came from a research effort that involved developing a new survey methodology to collect evacuation behavior data [13]. The study 
collected behavioral data from a total of 300 households that were sampled by using a sampling frame of telephone numbers. The data was collected using a mail out mail back questionnaire between August and October of 2009. In contrast to Hurricane Andrew data, the data for hurricane Gustav was collected from a total of ten parishes in the New Orleans area. The behavioral data was supplemented with time dependent emergency managers' decisions using newspaper archives and Hurricane Gustav characteristics using National Hurricane Center's Web archives.

\subsection{Comparison of Hurricane Gustav and Andrew Characteristics}

As reported by the National Hurricane Center, Hurricane Andrew originated from a tropical depression over the central Atlantic on August 11, 1992, and became a tropical storm six days later [14]. After turning westward Andrew entered a stage of rapid intensification to a category 5 hurricane near the Bahamas and made its first landfall in Elliott Key, Florida, the first in a series of three landfalls over a course of five days. After passing over Elliot Key it made landfall in Homestead, Florida, just south of Miami, as a category 4 hurricane and inflicted catastrophic damage on that community. It then entered and Gulf and before making its final landfall near Morgan City, Louisiana on August 26, 1992, Andrew threatened coastal parishes of Louisiana, Mississippi and Alabama and presented several evacuation decision-making challenges to emergency managers of coastal parishes resulting from uncertainty in the projected path, forecast intensity, and landfall location. These factors combined with other contextual factors resulted in evacuation of most of the coastal parishes in Louisiana, South-East Texas, Mississippi and Alabama.

Hurricane Gustav formed on the morning of August 25, 2008, about 260 miles from Haiti, and rapidly strengthened into a tropical storm that afternoon and into a hurricane early on August 26 [15]. Before entering the Gulf of Mexico, Gustav made landfall twice in Cuba and by the early hours of August 31, it entered the Gulf of Mexico as a category 4 hurricane. During August 31, the storm moved in a northwesterly direction slightly losing its strength and downgrading into a category 3 hurricane. On the evening of August 31, Gustav weakened to a category 2 hurricane and remained at that intensity until landfall along the Louisiana coast as a category 2 hurricane near Cocodrie at about 9:30 a.m [15]. Gustav had a steady path and consistent forecasts of landfall and intensity over a five-day period. This gave ample time for emergency managers and government officials to prepare and urge coastal residents to evacuate. In addition to these factors, the lessons learned from the catastrophic storm Katrina in the recent past highly motivated government officials to act promptly and to vigorously disseminate risk messages about approaching storm.

\subsection{Preparations for Hurricane Andrew and Gustav}

Public officials at local, state and federal level closely monitored Hurricane Andrew after it inflicted severe damage in the Homestead community of Florida. The uncertainty associated with the storm's landfall location and projected intensification of storm's strength prompted emergency officials to alert residents in coastal parishes of Louisiana, Mississippi, Alabama and Orange and Jefferson counties in Texas. Consequently, the local emergency managers and government officials issued evacuation orders in the areas that were considered to be facing high storm surge risk in coastal parishes. Then Mayor of Grand Isle announced mandatory evacuations early Monday, August 24th, for the entire Grand Isle area when the storm was about 48 hours away from making landfall [16]. Parallel to the efforts of Grand Isle, St. Mary parish and Vermillion parish announced mandatory evacuation orders of all the areas not protected by the levee system [16]. The orders from public officials in coastal parishes resulted in evacuation of people across all 
the jurisdictions that were considered to be under threat from storm surge and thus caused traffic jams on important evacuation routes in the area.

Going into the 2008 hurricane season public officials involved with emergency evacuation displayed more proactive interest in preparation and public outreach due to the increased criticism of their failure in responding to Hurricane Katrina in the previous years. Lessons learned following Katrina clearly prompted government officials to prepare proactively when hurricane Gustav presented a threat in the last week of August 2008. When hurricane Gustav was five days away from landfall and still looming in the Gulf of Mexico the newly elected governor appeared on TV and urged people to start preparing for the approaching storm either by stocking supplies or by voluntarily evacuating [17]. This announcement combined with the recent memory of catastrophic damage to the New Orleans city prompted public to prepare or voluntarily evacuate. In the time leading up to Gustav's landfall, the Governor appeared several times on TV and made several announcements about preparatory activities taken up by government officials. Parallel to governor's declarations in a series of evacuation orders, St. Tammany and Lafourche were the first parishes to announce mandatory evacuations on Friday when storm was about 60 hours away from landfall [18]. Tangipahoa, St. Tammany, Jefferson and Orleans parish issued evacuation orders following those of Terrebonne and Lafourche. But the news archives gathered from archived newspaper articles showed that majority of people left New Orleans and other parishes by Saturday evening even before major public officials declared mandatory evacuation orders in their respective parishes [19]. This information combined with the evacuation pattern observed confirms the significant influence of public officials on evacuation timing and evacuation decision as reported by other research [20].

\section{Model Formulation and Proposed Specifications}

The discrete choice model used in this study, a time dependent nested logit model (TDNLM), is a state-of-the-art time-dependent evacuation demand model that has the ability to consider several time dependent factors that influence the evacuation decision while allowing them to be correlated over time. The TDNLM is derived by postulating that a household, when considering evacuation in the face of an approaching storm, considers both existing conditions and forecast conditions of a storm and then compares the utility of evacuating in the existing time period with the utility of not evacuating and chooses the option that maximizes utility [21].

To illustrate the mathematical formulation of the model, consider household $n$ assessing whether to evacuate or not in three time periods $\mathrm{t} 1$, $\mathrm{t} 2$, and $\mathrm{t} 3$, where the time is measured in time to expected landfall. Thus, the time periods occur in reverse chronological order. Let the utility of household $n$ evacuating in time period $t 1$ be $\mathrm{U}_{\mathrm{ne} 1}$, and the utility of staying be $\mathrm{U}_{\mathrm{ns} 1}$. Likewise, let the utility of evacuating in time period $t 2$ and $t 3$ be $U_{n e 2}$ and $U_{n e 3}$, respectively, and the utility of staying in $t 2$ and $t 3$ be $\mathrm{U}_{\mathrm{ns} 2}$ and $\mathrm{U}_{\mathrm{ns} 3}$, respectively. The utility of vacuating in time period 1 is decomposed into an observed and an unobserved portion as shown in the following equation:

$$
\mathrm{U}_{\mathrm{ne} 1}=\mathrm{V}_{\mathrm{ne} 1}+\varepsilon_{\text {ne1 }}
$$

and similarly, the utility of staying in time period 1 is decomposed into an observed and an unobserved portion, but also includes a term $\left(\mathrm{LS}_{2}\right)$ which, in accordance with nested logit theory, captures the impact that choosing to stay in the earlier time period (t2) has on the utility to stay in $\mathrm{t} 1$, if any [6].

$$
\mathrm{U}_{\mathrm{ns} 1}=\mathrm{V}_{\mathrm{ns} 1}+\varepsilon_{\mathrm{ns} 1}+\mathrm{LS}_{2}
$$


Where $\mathrm{V}_{\text {ns } 1}$ is the observed portion of utility which in turn is a function of explanatory variables, and $\varepsilon_{\mathrm{ns}}$ is the unobserved portion of the utility that is assumed to be follow a Gumbel distribution.

$\mathrm{LS}_{2}$ is the $\log$ sum term defined as $\mathrm{LS}_{2}=\lambda \ln \left(\exp \left(\mathrm{V}_{\text {ne2 }}\right)+\exp \left(\mathrm{V}_{\mathrm{ns} 2}\right)\right)$. The $\log$ sum term is often referred to as the expected utility because it is the expected utility of choosing the lower nest which, in this case, is the expected utility of the next time period. The parameter $\lambda$ is estimated in the model estimation process and reflects, by the value of $(1-\lambda)$, the degree of correlation between the utilities of successive time periods [6].

Once the utility of evacuating and staying is decomposed into individual portions, invoking random utility maximizing theory leads to the marginal probability of evacuating in time period 1 being expressed as:

$$
\begin{aligned}
P_{n e 1} & =\operatorname{Prob}\left(U_{n e 1} \geq U_{n s 1}\right) \\
& =\operatorname{Prob}\left(V_{n e 1}+\varepsilon_{n e 1} \geq V_{n s 1}+\varepsilon_{n s} 1+L S_{2}\right)
\end{aligned}
$$

and because $\varepsilon_{\text {nel }}$ and $\varepsilon_{\text {ns1 }}$ are assumed to be Gumbel distributed, the probability of evacuating can be further reduced to a logit form as shown below.

$$
P_{n e 1}=\frac{\exp ^{V n e 1}}{\exp ^{V}{ }_{n e 1}+\exp ^{V} n s 1+L S_{2}}
$$

Similarly, the marginal probability of evacuating in time period t 2 can be derived as described above and expressed mathematically as:

$$
P_{n e 2}=\frac{\exp ^{V_{n e 2}}}{\exp ^{V_{n e 2}+\exp ^{V} n s 2^{+L S_{3}}}}
$$

where $\mathrm{LS}_{3}=\lambda \ln \left(\exp \left(\mathrm{V}_{\text {ne } 3}\right)+\exp \left(\mathrm{V}_{\mathrm{ns} 3}\right)\right)$

And, finally, the marginal probability of evacuating in time period 3 is

$$
P_{n e 3}=\frac{\exp ^{V} \text { ne3 }}{\exp ^{V} \text { ne3 }+e x p^{V} n s 3}
$$

Once the marginal probabilities are known then the conditional probability of evacuating in time period 1,2 , and 3 can be expressed as follows

$$
\begin{gathered}
\mathrm{P}_{\text {cne1 }}=\mathrm{P}_{\text {ne1 }} \\
\mathrm{P}_{\text {cne2 }}=\left(1-\mathrm{P}_{\text {ne1 }}\right) * \mathrm{P}_{\text {ne2 }} \\
\mathrm{P}_{\text {cne3 }}=\left(1-\mathrm{P}_{\text {ne1 } 1}\right) *\left(1-\mathrm{P}_{\mathrm{n} 2}\right) *\left(\mathrm{P}_{\mathrm{ne} 3}\right)
\end{gathered}
$$

The behavioral parameters associated with each variable in the utility functions $V_{n e}$ and $\mathrm{V}_{\mathrm{ns}}$ as well as the parameter $\lambda$ can be derived using a log likelihood estimation routine. If one considers a sample of $\mathrm{N}$ households the log likelihood expression can be written as

$$
\mathrm{L}(\beta)=\prod_{n=1}^{N} \prod_{t=1 . . T} P_{n e t}^{y_{n i}}
$$

Where $\mathrm{y}_{\mathrm{ni}}=1$ if household $\mathrm{n}$ chooses to evacuate in time interval $\mathrm{t}$ and 0 otherwise, and $\mathrm{P}_{\text {net }}$ is the marginal probability of evacuating in time interval $\mathrm{t}$. 


\subsection{Model Specification and Estimation Results}

A variety of behavioral and risk factors were considered for inclusion in the different model specifications considered in this study. The final candidate model specifications for comparison are shown in Table 1. The rationale behind using the factors shown in the table was the belief that the predictive performance of a model is maximized when the demands on available information in the application context includes data that can be obtained as accurately and reliably as possible. In other words if a researcher wants a transferred model to perform as well as possible, then the data in the application context should be available in an accurate and reliable form. For example, even though it is desirable to have socio-demographic factors that might have an influence on an evacuation decision, it may not be possible, or even plausible, to get forecasts of what the distribution of income, education level and age might be for the future application context. Moreover, since some variables in the TDNLM model are dynamic, an added requirement for those variables is that their dynamic behavior must be known in the forecast situation.

An important issue in transferring a time-dependent model like the TDNLM, is the number of time intervals that should be considered in the estimation context. If the number of time intervals considered for estimation is different to the number of time intervals in which data is available in the application context, the estimated parameters are not applicable since they are relevant to the duration of the time periods on which they were estimated. Therefore, to keep the consistency between the estimation (hurricane Gustav data) and application context (hurricane Andrew data), and also from experience gained in previous research, the total number of time intervals were limited to 14 with each time interval being 6 hours long, thereby making the total analysis time period equal to 84 hours.

After considering several model specifications, and considering explanatory variables that have proven to be important in the past, six different model specifications as shown in Table 2 were developed to test for temporal and geographic transferability. The parameters of the explanatory variables used in all the model specifications were found to have the expected sign. The t-statistics for each variable are shown in parentheses in the table. Not all the variables were found to be significant but they were retained because previous research has indicated that these variables play an important role in a households' choice of departure time [5,20,21]. The estimated likelihood ratio index for all model specifications were similar and above 0.47 .

Table 1. Definition of Variables Specified in Demand Models

\begin{tabular}{|l|l|}
\hline Log(timedepdist) & $\begin{array}{l}\text { Lognormal transformation of the straight line time-dependent } \\
\text { distance from the center of a storm to a household's geographical } \\
\text { location. The location and scale parameters used for the lognormal } \\
\text { distribution are 6 and 0.1, respectively. }\end{array}$ \\
\hline Timedepdum & $\begin{array}{l}\text { A dummy variable that is equal to zero if the time-dependent straight } \\
\text { line distance from the center of a storm to a household's } \\
\text { geographical location is either greater than } 800 \text { miles or less than } \\
150 \text { miles, and equals 1 when the distance is between } 800 \text { and } 150 \\
\text { miles. }\end{array}$ \\
\hline HC & $\begin{array}{l}\text { Indicates the time-dependent hurricane category on a scale of 1 to 5 } \\
\text { particular time period and is coded as a dummy variable. If a } \\
\text { voluntary or mandatory evacuation order was in effect for a } \\
\text { particular time period it is coded as 1, and if no evacuation order was } \\
\text { issued for that time period, it is coded as zero. }\end{array}$ \\
\hline Tod1 & $\begin{array}{l}\text { A dummy variable indicating the time of day of the time period; it is } \\
\text { coded as 1 if time of day is between 12:00 a.m. and 6:00 a.m. and }\end{array}$ \\
\hline
\end{tabular}




\begin{tabular}{|l|l|}
\hline & zero otherwise \\
\hline Tod2 & $\begin{array}{l}\text { A dummy variable which is coded 1 if time of day of the time period } \\
\text { is between 6:00 a.m and 12:00 p.m. otherwise it is coded as zero. }\end{array}$ \\
\hline Tod3 & $\begin{array}{l}\text { A dummy variable coded as1 if time of day of the time period is } \\
\text { between 12:00 p.m. and 6:00 p.m. and zero otherwise }\end{array}$ \\
\hline Const & Alternative Specific Constant \\
\hline
\end{tabular}

Table 2. Model Specifications and their Corresponding Test Statistics

\begin{tabular}{|c|c|c|c|c|c|c|}
\hline Variables & Model (1) & Model (2) & Model (3) & Model (4) & Model (5 ) & Model (6) \\
\hline $\begin{array}{l}\text { Log(timedepdi } \\
\text { st) }\end{array}$ & $\begin{array}{l}1236.49 \\
(3.54)\end{array}$ & $\begin{array}{l}1091.59 \\
(4.30)\end{array}$ & $740.05(2.75)$ & & & \\
\hline Timedepdum & & & & $\begin{array}{l}1.00 \\
(2.79)\end{array}$ & $\begin{array}{l}1.00 \\
(2.42)\end{array}$ & $\begin{array}{l}1.00 \\
(2.13)\end{array}$ \\
\hline $\mathrm{HC}$ & $\begin{array}{l}0.28 \\
(1.80) \\
\end{array}$ & $\begin{array}{l}0.35 \\
(2.65) \\
\end{array}$ & $\begin{array}{l}0.28 \\
(1.91) \\
\end{array}$ & $\begin{array}{l}0.27 \\
(1.91) \\
\end{array}$ & $\begin{array}{l}0.27 \\
(1.89) \\
\end{array}$ & $\begin{array}{l}0.16 \\
(0.877)\end{array}$ \\
\hline Combord & $\begin{array}{l}1.51 \\
(5.01)\end{array}$ & $\begin{array}{l}1.59 \\
(5.38)\end{array}$ & $\begin{array}{l}1.39 \\
(4.73)\end{array}$ & $\begin{array}{l}1.13 \\
(3.46)\end{array}$ & $\begin{array}{l}1.46 \\
(4.068)\end{array}$ & $\begin{array}{l}1.44 \\
(3.37)\end{array}$ \\
\hline Tod1 & $\begin{array}{l}2.16 \\
(4.79) \\
\end{array}$ & $\begin{array}{l}1.36 \\
(4.56) \\
\end{array}$ & & & $\begin{array}{l}1.42 \\
(4.34) \\
\end{array}$ & $\begin{array}{l}2.24 \\
(3.64) \\
\end{array}$ \\
\hline Tod2 & $\begin{array}{l}2.38 \\
(5.69)\end{array}$ & $\begin{array}{l}1.59 \\
(6.36)\end{array}$ & $\begin{array}{l}1.04 \\
(4.89)\end{array}$ & $\begin{array}{l}1.29 \\
(5.74)\end{array}$ & $\begin{array}{l}1.87 \\
(5.64)\end{array}$ & $\begin{array}{l}2.66 \\
(5.25)\end{array}$ \\
\hline Tod3 & $\begin{array}{l}1.24 \\
(2.90)\end{array}$ & & & & & $\begin{array}{l}1.14 \\
(2.09)\end{array}$ \\
\hline Lambda & $\begin{array}{l}0.78 \\
(13.16)\end{array}$ & $\begin{array}{l}0.79 \\
(14.96)\end{array}$ & $\begin{array}{l}0.82 \\
(17.42)\end{array}$ & $\begin{array}{l}0.81 \\
(15.93)\end{array}$ & $\begin{array}{l}0.74 \\
(12.25)\end{array}$ & $\begin{array}{l}0.70 \\
(9.30)\end{array}$ \\
\hline Const & $\begin{array}{l}-5.66 \\
(-7.82) \\
\end{array}$ & $\begin{array}{l}-4.98 \\
(-8.16)\end{array}$ & $\begin{array}{l}-3.79 \\
(-7.71)\end{array}$ & $\begin{array}{l}-3.80 \\
(-6.99)\end{array}$ & $\begin{array}{l}-4.98 \\
(-7.49)\end{array}$ & $\begin{array}{l}-5.69 \\
(-7.24)\end{array}$ \\
\hline $\begin{array}{l}\text { No. of } \\
\text { Observations }\end{array}$ & 4320 & 4320 & 4320 & 4320 & 4320 & 4320 \\
\hline $\begin{array}{l}\text { Log Likelihood } \\
\text { at Zero }\end{array}$ & 1144.8 & 1144.4 & 1143.6 & 1143.6 & 1144.4 & 1144.4 \\
\hline $\begin{array}{l}\text { Log Likelihood } \\
\text { at Convergence }\end{array}$ & 590.4 & 595.6 & 608.1 & 610.3 & 597.7 & 594.2 \\
\hline $\begin{array}{l}\text { Likelihood } \\
\text { Ratio Index }\end{array}$ & 0.48 & 0.48 & 0.47 & 0.47 & 0.48 & 0.48 \\
\hline
\end{tabular}

Models 4, 5, and 6 have an explanatory variable called timedepdum as defined in Table 1. The variable captures the influence of distance between the center of a storm and a household's geographical location, but recognizes there is a critical distance at which the proximity of the storm is most influential. Instead of simply using time dependent distance, the authors instituted a dummy variable that indicated whether or not the distance between center of the storm and the geographical location of a household is between 800 miles and 150 miles or not (1 when the storm was between 800 and 150 miles from landfall, 0 when it was not). This variable was considered for inclusion to obviate the need to make an assumption about the nature of relationship between distance from center of the storm to a household location and probability of evacuation. That is, if one uses a lognormal transformation of distance, as done in the variable $\log$ (timedepdist) in models 1,2, and 3, then one has to make the assumption about the type of distribution and as well as its associated location and scale parameters. On the other hand, if no transformation of distance is assumed, then only the cutoff points specifying the region in 
which the presence of a storm would motivate evacuation (150 miles and 800 miles) had to be made.

The rationale for transforming the distance to the storm as done in both the $\log$ (timedepdist) and timedepdum variables is that there is, intuitively, a non-linear relationship between the distance to an oncoming storm and the danger it poses. When a hurricane is far away, any advance brings little additional concern. At the same time, when a hurricane is close, evacuation is no longer an effective means of mitigating the effects of the hurricane, so the advance of a hurricane in the last 100 miles or so prompts little additional evacuation. The consequence is that most evacuation is prompted in the middle distances to the storm and the lognormal transformation of distance and the dummy variable of distance are an attempt to cater for that behavioral response.

Table 3 shows estimation results obtained for Hurricane Andrew. The model specifications used in the estimation were the same as the ones used in estimation of models on Hurricane Gustav. As can be seen from comparison of parameter values from corresponding models in Tables 2 and 3, some are similar and others are different from each other. An objective means of comparing the parameter values is needed and this is provided by the likelihood ratio test. The likelihood ratio test hypothesizes the identity of vector of parameters of two identically specified models estimated on two different data sets using chi-squared test statistic with degrees of freedom equal to the number of parameters in the mode. That is:

$$
\begin{gathered}
H_{0}: \beta_{\text {Gustav }}=\beta_{\text {Andrew }} \\
H_{A}: \beta_{\text {Gustav }} \neq \beta_{\text {Andrew }} \\
\chi_{k}^{2} \sim-2\left[L L_{\text {pooled }}-L L_{\text {Andrew }}-L L_{\text {Gustav }}\right.
\end{gathered}
$$

where $K=$ no. of parameters in the model and $L L_{\text {pooled }}$ $=$ loglikelihood of the model at convergence estimated on the pooled Gustav and Andrew data

The chisquare test conducted at $95 \%$ significance level was unable to reject the null hypothesis that parameter values estimated from Andrew and Gustav were equal for Model 1 but rejected the null hypotheses for all other model specifications.

Table 3. Model Specifications and their Corresponding Test Statics for Hurricane Andrew

\begin{tabular}{|l|l|l|l|l|l|l|}
\hline Variables & Model (1) & Model (2) & Model (3) & Model (4) & Model (5) & Model (6) \\
\hline Log(timedepdist) & $\begin{array}{l}1043.74 \\
(2.89)\end{array}$ & $\begin{array}{l}1113.19 \\
(3.31)\end{array}$ & $\begin{array}{l}1023.26 \\
(3.62)\end{array}$ & & & \\
& & & & 1.18 & 1.26 & \\
\hline Timedepdum & & & & $(2.76)$ & $(3.09)$ & $\begin{array}{l}1.22 \\
(3.19)\end{array}$ \\
\hline HC & 0.19 & 0.15 & 0.10 & 0.075 & 0.01 & 0.01 \\
& $(0.82)$ & $(0.63)$ & $(0.54)$ & $(0.37)$ & $(0.04)$ & $(0.03)$ \\
\hline Combord & 0.25 & 0.42 & 0.016 & 0.01 & 0.01 & 0.01 \\
& $(0.47)$ & $(0.63)$ & $(0.032)$ & $(0.017)$ & $(0.02)$ & $(0.02)$ \\
\hline Tod1 & 2.00 & 1.73 & & & 1.67 & 1.97 \\
& $(3.54)$ & $(3.86)$ & & & $(4.81)$ & $(3.03)$ \\
\hline Tod2 & 1.85 & 1.56 & 0.74 & 0.69 & 1.47 & 1.77 \\
& $(3.21)$ & $(3.87)$ & $(2.27)$ & $(2.39)$ & $(4.42)$ & $(2.53)$ \\
\hline Tod3 & 0.66 & & & & & 0.56 \\
& $(0.84)$ & & & & & $(0.65)$ \\
\hline Lambda & 0.90 & 0.85 & 0.82 & 0.89 & 0.95 & 0.96 \\
\hline
\end{tabular}




\begin{tabular}{|l|l|l|l|l|l|l|}
\hline & $(9.2)$ & $(6.7)$ & $(8.05)$ & $(6.30)$ & $(16.25)$ & $(19.92)$ \\
\hline Const & -4.27 & -4.56 & -4.03 & -3.54 & -3.38 & -3.33 \\
$(-3.31)$ & $(-3.1)$ & $(-4.6)$ & $(-3.24)$ & $(-4.08)$ & $(-4.00)$ \\
\hline $\begin{array}{l}\text { No. of } \\
\text { Observations }\end{array}$ & 1995 & 1995 & 1995 & 1995 & 1995 & 1995 \\
\hline $\begin{array}{l}\text { Log Likelihood at } \\
\text { Zero }\end{array}$ & 640.39 & 640.39 & 640.39 & 640.39 & 640.38 & 640.38 \\
\hline $\begin{array}{l}\text { Log Likelihood at } \\
\text { Convergence }\end{array}$ & 257.06 & 257.56 & 269.4 & 271.03 & 257.75 & 257.29 \\
\hline $\begin{array}{l}\text { Likelihood Ratio } \\
\text { Index }\end{array}$ & 0.59 & 0.59 & 0.58 & 0.57 & 0.59 & 0.59 \\
\hline
\end{tabular}

\subsection{Measures of Transferability}

The estimation statistics for six different model specifications indicate a relatively good fit for all models. However, while the models all display a relatively good fit, will they transfer equally well? To address this issue the authors measured the transferability of the models estimated on Gustav data and applied them to the cases in the Andrew data. Transferability was measured using four measures of transferability as suggested by Koppelman and Wilmot [22]. Transfer rho-square, Transfer Index (TI), Transfer Test Statistic (TTS), and Root mean square error (RMSE) were the four metrics used to assess the transferability of the six different model specifications. The metrics used for ranking models are defined as follows

Transfer $\rho^{2}=1-\frac{L L_{l}\left(\beta_{t}\right)}{L L_{l}(\text { Base })}$

Where,

$L L_{l}\left(\beta_{t}\right)=\log$ likelihood of a model transferred from context $t$ (Hurricane Gustav) to the local situation/application context l (Hurricane Andrew)

$L L_{l}$ (Base) $=\log$ likelihood of the equal shares or market shares model in the local situation/ application context $l$

The transfer index is defined as the ratio of the transfer rho square value to the local rho square value for a model with the same specification

$$
\text { Transfer Index }=\frac{\text { transfer } \rho^{2}}{\rho^{2}} \text { where }
$$

transfer $\rho^{2}$ is defined previously and

$\rho^{2}=$ local likelihood ratio index value for a model with same specification $=1-\frac{L L_{l}\left(\beta_{l}\right)}{L L_{l}(\text { Base })}$

The Transfer Test Statistic is used to test whether there is a significant difference between local model parameters and the assumed fixed values of the transfer parameters. The Transfer Test Statistic tests the hypothesis that transferred parameters are not significantly different from the local parameters and the test statistic is chi-squared distributed with degrees of freedom equal to the number of transferred parameters and defined as

Transfer Test Statistic $=-2\left[L L_{l}\left(\beta_{t}\right)-L L_{l}\left(\beta_{l}\right)\right]$ 
Where $L L_{l}\left(\beta_{l}\right)=\log$ likelihood obtained by parameter estimation in the local situation or application context

Root Mean Square Error $=\sqrt{\frac{\sum_{i=1}^{n}\left(x_{i, p r e d}-x_{i, o b s}\right) 2}{n}}$

$\mathrm{X}_{\mathrm{i} \text {,pred }}=$ number of households predicted to evacuate in time interval $\mathrm{i}$

$\mathrm{X}_{\mathrm{i}, \mathrm{obs}}=$ number of households observed to evacuate in time interval $\mathrm{i}$

$\mathrm{n}=$ total number of time intervals

The estimated metrics shown in Table 4 identify model 1 as best based on all the four metrics used to measure transferability. Moreover, the hypothesis that transferred model parameters are not significantly different from local parameters could not be rejected for the model 1 at the $95 \%$ level of significance. The table chi-squared statistic values at the 95\% level of significance for the appropriate number of parameters in each model is shown in parentheses in the TTS column in Table 4. From these results it can be seen that all models except model 1 reject the hypothesis that the transfer parameters and the local parameters are the same. The transfer rho-squared and TI values indicate relatively good transferability for model 1. The RMSE indicates that the average error in predictions in each 6-hour time period varies from 3.53 households in model 1 to 6.29 households in model 4.

A graph comparing the observed and model 1 predictions is shown in Figure 1. The diurnal fluctuation in evacuation closely matched the observed pattern although the transferred model over-predicted on the first day (22 predicted, 11 observed). Model 1 predicted a total of 87 household evacuations when 72 were observed. At the same time the model 4, that did not have variables tod 1 and tod3 in addition to transformation of time dependent distance performed badly on transfer test static and root mean square error. As shown in Figure 2, it predicted a total of 90 evacuations when 72 were observed. Most of the over prediction occurred on the first and second day (23 predicted and 11 observed on day one, and 39 predicted and 28 observed on the second day). This might be due the fact that the cutoff points used to capture the relationship between distance from the center of the storm to a household's location did not transfer well in the application context. What was most surprising here is that all the models that used lognormal transformation of distance from center of a storm to a household's geographical location transferred really well and produced superior root mean square error statistics as compared to the specifications without such transformation.

Table 4. Results from Transferring Gustav Context to Andrew Context

\begin{tabular}{|l|l|l|l|l|}
\hline Model & \multicolumn{1}{|c|}{ Transfer $\rho^{2}$} & \multicolumn{1}{|c|}{ TI } & $\begin{array}{c}\text { Transfer Test Statistic } \\
\left(\chi^{2} 0.95\right)\end{array}$ & RMSE \\
\hline Model 1 & 0.58 & 0.98 & $15.14(15.51)$ & 3.53 \\
\hline Model 2 & 0.58 & 0.98 & $15.28(14.07)$ & 3.54 \\
\hline Model 3 & 0.56 & 0.97 & $18.8(12.59)$ & 5.03 \\
\hline Model 4 & 0.55 & 0.96 & $27.16(12.59)$ & 6.29 \\
\hline Model 5 & 0.55 & 0.92 & $59.8(14.07)$ & 4.62 \\
\hline Model 6 & 0.57 & 0.96 & $27.34(15.51)$ & 5.10 \\
\hline
\end{tabular}




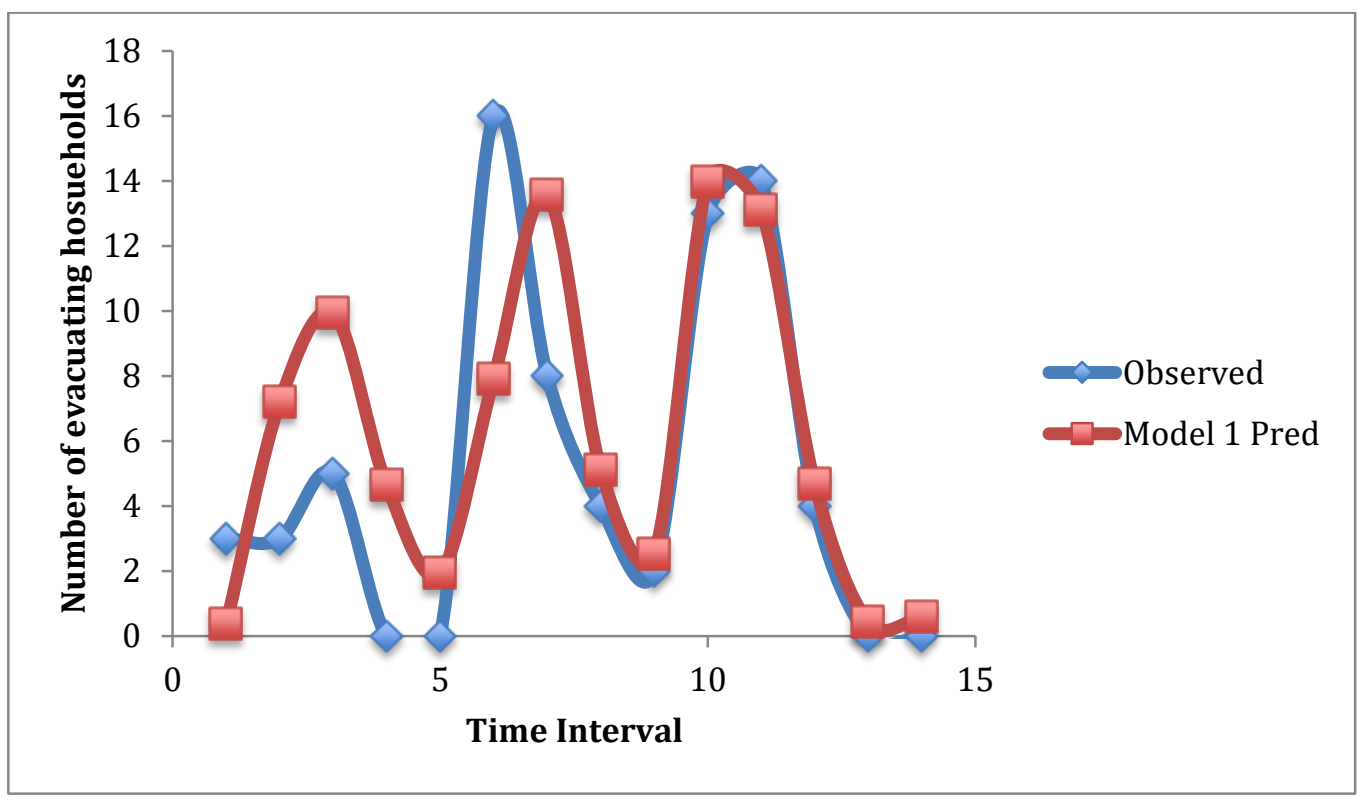

Figure 1. Comparison of Observed versus Predicted for Model 1

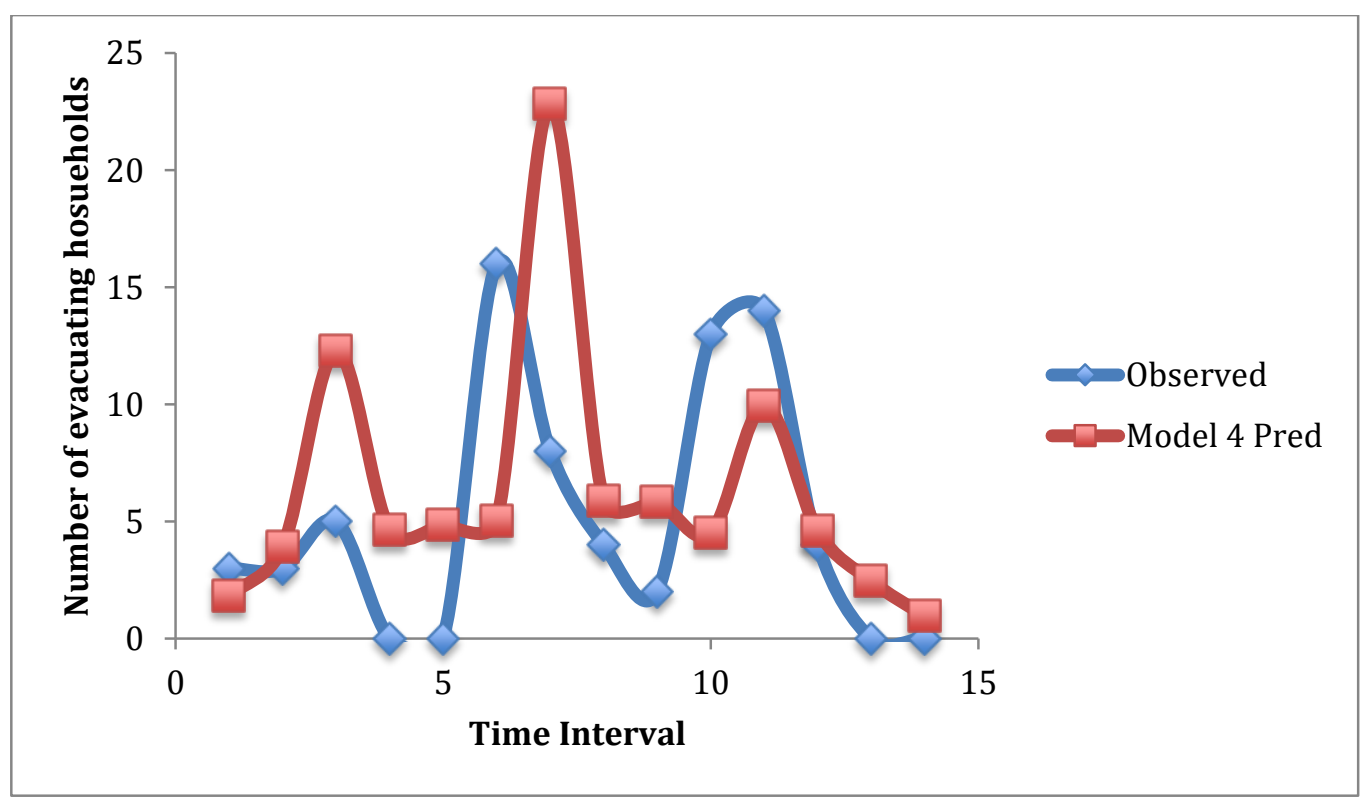

Figure 2. Comparison of Observed versus Predicted for Model 4

\section{Summary and Conclusions}

The main objective of this paper was to examine the relationship between model specification and the temporal/geographic transferability of a time-dependent nested logit model of hurricane evacuation demand. To achieve the objective, six different model specifications were considered, model parameters were estimated using Hurricane Gustav data, and then models with the estimated parameters were transferred to Hurricane Andrew data. The Transfer Test Statistic identified model 1 as superior to the other models. The lowest RMSE value of 3.53 was noted for model 1 and the highest of 6.29 was noted for model 4 . Even though metrics that measure transferability in a relative manner, such as Transfer rho-square and Transfer Index, were similar among the models, absolute measures such as the 
Transfer Test Statistic and RMSE, clearly distinguished model 1 from the other models.

It is also worthwhile to mention here that Gustav had high evacuation rates early on because the authorities were aggressive in getting people to evacuate because it was only 3 years after Katrina. This likely led to inflated responses to early evacuation in the Gustav data which seems to be reflected here in prediction of evacuation rates for Hurricane Andrew in early time intervals.

One of the important findings of this study is that model specifications that make very modest demands on data availability in an application context can still transfer relatively well. The information required in the application context in the models tested in this study included storm characteristics that are typically provided by the National Hurricane Center (dynamic position, strength, forward speed, and path of the storm), the location of individual households, and time-dependent decisions made by emergency managers regarding which areas to evacuate and when to issue the evacuation order. This information is relatively easy to provide either in a historical context (i.e., analyzing past storms) or in real time as a storm develops and the model is used to estimate the evacuation demand that would develop given different scenarios of the storm and emergency manager decisions.

The results reported in this study are only applicable when extended to a situation where models are developed and applied at a disaggregate level. It is not advisable to apply a disaggregate model on aggregate input data because of the non-linear nature of discrete choice models.

The results presented in this study should prove useful to evacuation modelers, emergency managers, and other evacuation policy designers and analysts in identifying appropriate model specifications when transferring demand models from one context to another context.

\section{Acknowledgments}

The authors acknowledge the financial support of Louisiana Transportation Research Center for making this research possible.

\section{References}

[1] P. Murray-Tuite, W. Yin, S. V. Ukkusuri and H. Gladwin, "Changes in Evacuation Decisions Between Hurricanes Ivan and Katrina", Transportation Research Record: Journal of the Transportation Research Board, vol. 2312, no. 1, (2012), pp. 98-107.

[2] V. V. Dixit, C. Wilmot and B. Wolshon, "Modeling risk attitudes in evacuation departure choices", Transportation Research Record: Journal of the Transportation Research Board, vol. 2312, no. 1, (2012), pp. 159-163.

[3] S. Hasan and S. Ukkusuri, "Behavioral Model to Understand Household-Level Hurricane Evacuation Decision Making", Journal of Transportation Engineering, (2010) May, pp. 341-348.

[4] A. M. Sadri, S. V. Ukkusuri and P. Murray-Tuite, "A random parameter ordered probit model to understand the mobilization time during hurricane evacuation", Transportation Research Part C: Emerging Technologies, vol. 32, (2013), pp. 21-30.

[5] H. Fu, G. Wilmot and E. Baker Jay, "Sequential Logit Dynamic Travel Demand Model and Its Transferability”, Transportation Research Record: Journal of the Transportation Research Board, vol. 1977, (2006), pp. 17-26.

[6] M. Ben-Akiva and S. Lerman, "Discrete Choice Analysis: Theory and Application to Travel Demand", MIT Press, Cambridge, Massachusetts, (1985).

[7] S. Hasan and R. Mesa-Arango, "Transferability of hurricane evacuation choice model: Joint model estimation combining multiple data sources", Journal of Transportation Engineering, (2011) May, pp. 548-556.

[8] D. Mileti and J. Sorensen, "Communication of emergency public warnings. Landslides", Retrieved from http://emc.ed.ornl.gov/publications/PDF/CommunicationFinal.pdf, (1990).

[9] M. K. Lindell and R. W. Perry, "The protective action decision model: theoretical modifications and additional evidence", Risk Analysis : An Official Publication of the Society for Risk Analysis, vol. 32, no. 4, (2012), pp. 616-32. 
[10] M. Lindell, J. Lu and C. Prater, "Household decision making and evacuation in response to Hurricane Lili”, Natural Hazards Review, November, (2005), pp. 171-179.

[11] S. Huang, M. Lindell and C. Prater, "Household evacuation decision making in response to Hurricane Ike", Natural Hazards Review, (2012) November, pp. 283-296.

[12] M. D. Irwin and J. S. Hurlbert, "A Behavioral Analysis of Hurricane Preparedness and Evacuation in Southwestern Louisiana", Louisiana Population Data Center, (1995) September.

[13] R. Gudishala, "Development of A Time-Dependent, Audio-Visual, Stated Choice Method of Data Collection of Hurricane Evacuation Behavior", Ph.D. Dissertation, Department of Civil and Environmental Engineering, Louisiana State University, Baton Rouge, Louisiana, (2011) December.

[14] Rappaport, ED, Preliminary Report-Hurricane Andrew, http://www.nhc.noaa.gov/1992andrew.html. Accessed (2014) October 10.

[15] L. J. Beven II and B. T. Kimberlain, "Tropical Cyclone Report Hurricane Gustav"http://www.nhc.noaa.gov/pdf/TCR-AL072008_Gustav.pdf. Accessed July 2, 2014.

[16] Reports, From staff. "Area waiting Andrew In Buzz Of Preparation", Times-Picayune, The (New Orleans, LA) 25 Aug. 1992, NATIONAL: A9. NewsBank. Web. Accessed (2014) October 25.

[17] R. Zullo, "Lafourche and Terrebonne parishes begin evacuations", http://www.houmatoday.com/article/20080829/articles/808299951?template=printpicart. Acessed, (2014) July 05.

[18] J. Alfrod, "Jindal urges La. residents to prepare", http://www.houmatoday.com/article/20080827/ARTICLES/808270249. Accessed (2014) July 10.

[19] CBSNews, Gustav Sends Gulf Coast Residents Fleeing, http://www.cbsnews.com/news/gustav-sendsgulf-coast-residents-fleeing/. Accessed (2014) July 07.

[20] E. Baker, "Hurricane Evacuation Behavior", International Journal of Mass Emergencies and Disasters, vol. 9, no. 2, vol. 1991, pp. 287-310.

[21] R. Gudishala and C. Wilmot, "Comparison of Time-Dependent Sequential Logit and Nested Logit for Modeling Hurricane Evacuation Demand", Transportation Research Record: Journal of the Transportation Research Board, vol. 2312, no. 1, (2012), pp. 134-140.

[22] F. S. Koppelman and C. Wilmot, "Transferability Analysis of Disaggregate Choice Models", Transportation Research Record 895: Journal of the Transportation Research Board, vol. 1982, pp. 1823.

\section{Authors}

Ravindra Gudishala, Ravindra is a Research Associate in Department of Civil and Environmental Engineering at Louisiana State University, Baton Rouge. His research interests are in Evacuation Demand Modeling, Travel Demand Modeling, Discrete Choice Modeling, Innovative Methods of Behavior Data Collection and Time-Dependent Behavior Data Collection Methods. He obtained his Ph.D in Civil Engineering from Louisiana State University and has about 11 years of modeling and data collection experience.

Chester Wilmot, Chester Wilmot is a Professor in Department of Civil and Environmental Engineering at Louisiana State University, Baton Rouge. His research interests are in Hurricane Evacuation Demand Estimation, Traffic Safety Data Collection for Transportation Planning, Transferability of transportation planning data. He has about 40 years of experience in modeling and data collection 